\title{
Article \\ Comprehensive Performance Evaluation of Densified Liquid Hydrogen/Liquid Oxygen as Propulsion Fuel
}

\author{
Fushou Xie ${ }^{1,2, *}$ and Qiang Sun ${ }^{2}$ \\ 1 State Key Laboratory of Technologies in Space Cryogenic Propellants, Beijing 100028, China \\ 2 Institute of Refrigeration and Cryogenics, Xi'an Jiaotong University, Xi'an 710049, China; \\ sunqiang9716@stu.xjtu.edu.cn \\ * Correspondence: xiefushou@xjtu.edu.cn
}

check for updates

Citation: Xie, F.; Sun, Q. Comprehensive Performance Evaluation of Densified Liquid Hydrogen/Liquid Oxygen as Propulsion Fuel. Energies 2022, 15, 1365. https://doi.org/10.3390/ en15041365

Academic Editor: Talal Yusaf

Received: 13 January 2022

Accepted: 9 February 2022

Published: 14 February 2022

Publisher's Note: MDPI stays neutral with regard to jurisdictional claims in published maps and institutional affiliations.

Copyright: (c) 2022 by the authors. Licensee MDPI, Basel, Switzerland. This article is an open access article distributed under the terms and conditions of the Creative Commons Attribution (CC BY) license (https:// creativecommons.org/licenses/by/ $4.0 /)$.

\begin{abstract}
Densified liquid hydrogen/liquid oxygen is a promising propulsion fuel in the future. In order to systematically demonstrate the benefits and challenges of densified liquid hydrogen/liquid oxygen, a transient thermodynamical model considering the heat leakage, temperature rise, engine thrust, pressurization pressure of the tank, and wall thickness of tank is developed in the present paper, and the performance of densified liquid hydrogen/liquid oxygen as propulsion fuel is further evaluated in actual application. For liquid hydrogen/liquid oxygen tanks at different structural dimensions, the effects of many factors such as temperature rise during propellant ground parking, lift of engine thrust, mass reduction of the tank structure, and extension of spacecraft in-orbit time are analyzed to demonstrate the comprehensive performance of liquid hydrogen/liquid oxygen after densification. Meanwhile, the problem of subcooling combination matching of liquid hydrogen/liquid oxygen is proposed for the first time. Combining the fuel consumption and engine thrust lifting, the subcooling combination matching of liquid hydrogen/liquid oxygen at different mixing ratios and constant mixing ratios are discussed, respectively. The results show that the relative engine thrust enhances by $6.96 \%$ compared with the normal boiling point state in the condition of slush hydrogen with $50 \%$ solid content and enough liquid oxygen. The in-orbit time of spacecraft can extend about 2-6.5 days and 24-95 days for slush hydrogen with 50\% solid content and liquid oxygen in the triple point state in different cryogenic tanks, respectively. Due to temperature rise during parking, the existing adiabatic storage scheme and filling scheme for densification LH2 need to be redesigned, and for densification LO2 are suitable. It is found that there is an optimal subcooling matching relation after densification of liquid hydrogen/liquid oxygen as propulsion fuel. In other words, the subcooling temperature of liquid hydrogen/liquid oxygen is not the lower the better, but the matching relationship between $\mathrm{LH} 2$ subcooling degree and $\mathrm{LO} 2$ subcooling degree needs to be considered at the same time. It is necessary that the LO2 was cooled to $69.2 \mathrm{~K}$ and $54.5 \mathrm{~K}$, when the $\mathrm{LH} 2$ of $13.9 \mathrm{~K}$ and $\mathrm{SH} 2$ with $45 \%$ was adopted, respectively. This research provides theoretical support for the promotion and application of densification cryogenic propellants.
\end{abstract}

Keywords: densification; liquid hydrogen; liquid oxygen; comprehensive performance evaluation; subcooling combination matching

\section{Introduction}

Liquid hydrogen/liquid oxygen (LH2/LO2) is the most widely used as fuel for large launch vehicles because of its advantages of non-toxic, pollution-free, low cost, high specific impulse, and high thrust, whose specific impulse is $30-40 \%$ higher than of normal temperature propellants. Although cryogenic propellant has obvious advantages compared with the normal temperature fuel, most of the thermodynamic states in the application at the moment are near the boiling point temperature. Thus, there are still some disadvantages, such as low density, easy evaporation, difficult storage, and so on. At this time, researchers are often keen to use densified cryogenic propellant as propulsion fuel, and 
its thermodynamic performance will be significantly improved compared with the saturated sate, such as increasing its own density, reducing gasification pressure, increasing cooling capacity per unit volume, etc. Taking LH2, for example, the density and cooling capacity per unit volume can increase by $8.8 \%$ and $20 \%$, respectively, from the standard boiling point $(20.39 \mathrm{~K})$ to the triple point temperature $(13.8 \mathrm{~K})$. From the thermodynamic point of view of densified cryogenic propellants, it can be seen that the advantages of its thermodynamic performance are very significant, but the popularization effect is not ideal from the perspective of practical application.

The concept of densification cryogenic propellants began in the 1960s, and Carney [1] elaborated on the performance advantages of slush hydrogen (SH2) in terms of density and heat capacity. Keller [2] indicated SH2 with 50\% solid content used in the fourth stage of the Saturn V would reduce evaporation losses from $2.9 \mathrm{t}$ to $0.5 \mathrm{t}$ during orbital flight and increase payload by about $40 \%$. Friedlander [3] believed that the space shuttle could increase its payload by about $5 \%$ or $9 \%$, respectively, using the triple point LH2 or SH2. Wilken [4] suggested that the dry mass in the affected stages could be decreased by up to $27 \%$ and $30 \%$ for the adoption of densified $\mathrm{LH} 2 / \mathrm{LO} 2$ or $\mathrm{LO} 2 / \mathrm{LCH} 4$, respectively. Johnson [5] determined that the LCH4 should be cooled to $93 \mathrm{~K}$ from $111 \mathrm{~K}$ to extend in-orbit time on the lunar surface. Mustafi [6] explored the beneficial effect of subcooled cryogenic propellants on the launch pad for long-term storage of cryogenic propellants in space. Baik [7] reported that when the liquid hydrogen density increased to $8 \%$ and the liquid oxygen density increased to $10 \%$, the gross lift-off weight of a cryogenic rocket could reduce by up to $20 \%$. Lak [8] described that the increase of density for cryogenic propellants could reduce the mass of the rocket tank, and the decrease of gasification pressure could also reduce the tank mass and propellant residual weight. Xie [9-13] also conducted a lot of preliminary research work on the utilization of densified cryogenic propellants. Meanwhile, in the USA. Apollo program, Space Transportation System (STS) [14] Single-stage Reusable Launch Vehicle (RLV) [15-17], X-33 program [18-22], and Ares V launch vehicle [23,24] all conducted extensive analysis and demonstration about densified cryogenic propellants, and continued to invest in the large-scale production and preservation of $\mathrm{SH} 2$ [25-27].

Although many researchers identified the advantages of subcooled cryogenic propellants in reducing take-off weight and extending in-orbit time, the advantages were mainly considered from the simple ideal situation, such as the benefits from the increase of density and cooling capacity. However, in the evaluation analysis of subcooled LH2 and $\mathrm{LO} 2$, it is necessary to consider not only the improvement of thermodynamic performance but also its advantages and disadvantages in practical application, such as the parking temperature rise of subcooled cryogenic propellant, the effect on engine thrust and service life, a decrease of pressurization mass with helium, the combination matching of subcooled LH2 and LO2, etc. At present, except that the Falcon 9 rocket uses subcooled liquid oxygen and subcooled RP-1 [28], other cryogenic launch vehicles still use cryogenic propellant at the normal boiling point as fuel. Therefore, many researchers have questioned the practical application value of densification cryogenic propellants. Especially, there is still no unified understanding for potential performance enhancement of cryogenic launch vehicles when densification cryogenic propellants are used as fuels. Moreover, based on the team's previous research, it is found that there is a combined matching question about subcooling degree after densification of LH2 and LO2, which has not been reported previously. The subcooling degree of LH2 is not the lower, the better, and the subcooling degree of LO2 is also not the lower, the better. If the $\mathrm{LH} 2$ subcooling is too large, the mixing ratio during combustion cannot be guaranteed. Because the liquid hydrogen temperature decreases and the density increases, the mass of liquid hydrogen pumped in per unit time will be more when the turbine pump speed is constant. Therefore, the mixture ratio will change with the decrease of liquid hydrogen temperature. The existing storage tank is used to load subcooled liquid oxygen. If the subcooling degree is too large, the loading quality will be more. Considering the matching consumption of liquid hydrogen, there will be more residual mass. The excess cooling capacity and LO2 will be wasted, thus there should be 
the best matching relationship between the two as a propellant combination. Therefore, to fully understand the comprehensive performance advantages of cryogenic propellants after densification, a transient thermodynamic model is developed in the paper to evaluate its performance reasonably. The benefits and challenges of densified cryogenic propellants are discussed, and the issue of $\mathrm{LH} 2 / \mathrm{LO} 2$ combination matching about subcooling degree is furtherly analyzed.

\subsection{Transient Thermodynamic Model}

A cryogenic launch vehicle uses $\mathrm{LH} 2 / \mathrm{LO} 2$ as propulsion fuel. In order to quantitatively evaluate the comprehensive performances of the densified propellants, the application process of the densified cryogenic propellant is simplified into several single subsystem, and their thermodynamic models are constructed, respectively.

\subsection{Heat Leakage Model}

It is inevitable that some heat leakage can occur during the filling and parking of cryogenic propellants with even excellent passive insulation, and therefore, cryogenic propellants will always generate temperature rise. For subcooled cryogenic propellants, the greater the subcooling degree, the greater the temperature difference with the external environment, and the more serious the heat leakage.

The tank of the cryogenic launch vehicle can be simplified as a cylindrical structure with an outer layer of polyurethane insulation foam, as shown in Figure 1.

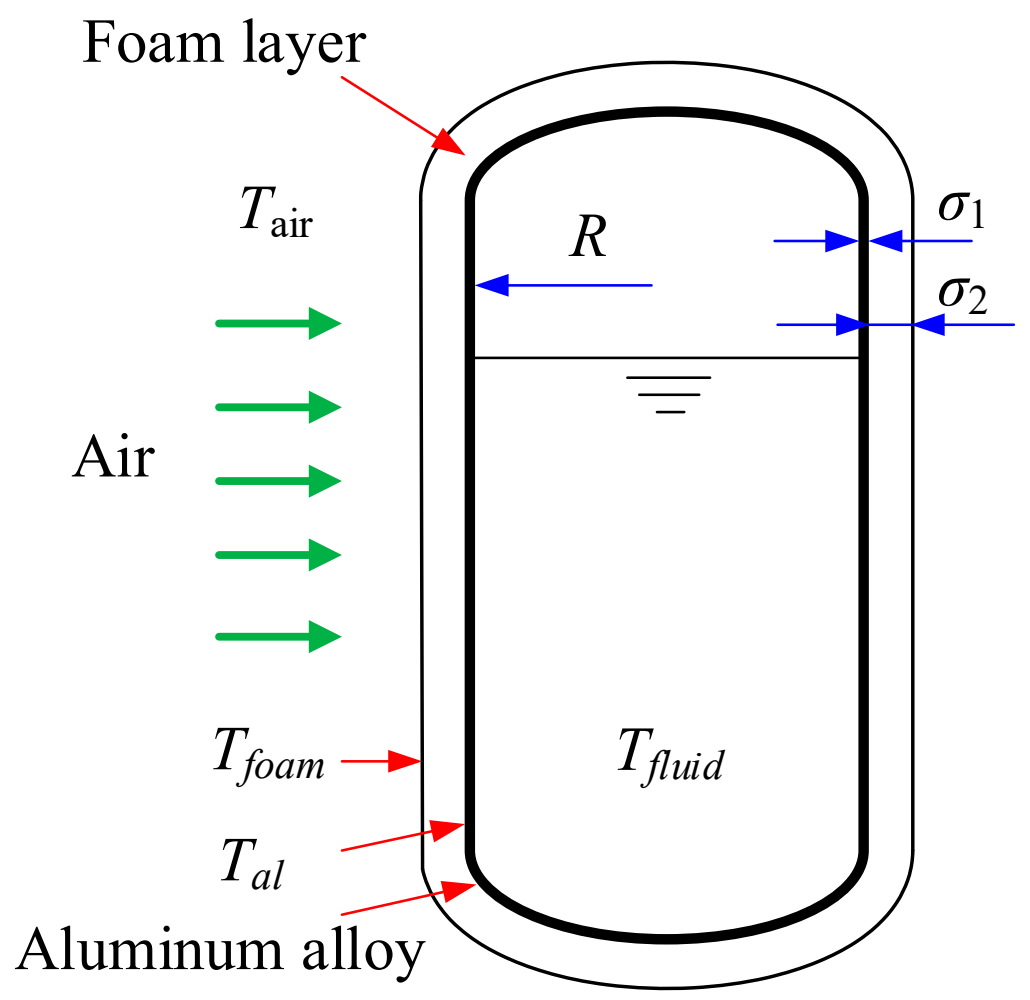

Figure 1. Schematic diagram of tank insulation.

Combined heat transfer could be written:

$$
Q_{z 1}=A_{z}\left(h_{f z}+h_{r z}\right)\left(T_{\text {air }}-T_{\text {foamz }}\right)
$$

where $Q_{z 1}$ is the combined heat transfer, $h_{f z}$ is the heat transfer coefficient of average convection, $h_{r z}$ is the heat transfer coefficient of average radiation, $A_{z}$ is the outside surface area, $T_{\text {air }}$ is the environmental temperature, and $T_{\text {foamz }}$ is the wall temperature of the foam layer. 
Heat conduction equation of insulation layer is given:

$$
Q_{z 2}=\frac{2 \pi\left(T_{\text {foamz }}-T_{\text {fluid }}\right) \times H}{\ln \left(\frac{R+\delta_{1}+\delta_{2}}{R+\delta_{1}}\right) / \lambda_{\text {foamz }}+\ln \left(\frac{R+\delta_{1}}{R}\right) / \lambda_{\text {alz }}}
$$

where $Q_{z 2}$ is the amount of heat conduction, $H$ is the tank height, $\lambda_{\text {foamz }}$ is the thermal conductivity of foam layer, $\lambda_{\text {alz }}$ is the thermal conductivity of aluminum alloy, $T_{\text {fluid }}$ is the temperature of tank fluids, $R$ is the radius of the tank, $\sigma_{1}$ is the thickness of aluminum alloy, and $\sigma_{2}$ is the thickness of foam layer.

When the density of foam material is $49.02 \mathrm{~kg} / \mathrm{m}^{3}$, the thermal conductivity of foam material is written from 20 to $300 \mathrm{~K}$ as follows:

$$
\lambda_{\text {foam }}=\left(6.862+0.1384 \times T-1.316 \times 10^{-4} \times T^{2}\right) \times 0.001
$$

The average thermal conductivity could be given using integral from $T_{\text {foamz }}$ to $T_{\text {fluid }}$ as follows:

$$
\begin{aligned}
\bar{\lambda}_{\text {foamz }} & =6.862 \times 10^{-3}+6.92 \times 10^{-5}\left(T_{\text {foamz }}+T_{\text {fluid }}\right) \\
& +4.387 \times 10^{-8}\left(T_{\text {foamz }}^{2}+T_{\text {foamz }} T_{\text {fluid }}+T_{\text {fluid }}^{2}\right)
\end{aligned}
$$

The thermal conductivity for aluminum alloy can be obtained from 20 to $300 \mathrm{~K}$ :

$$
\lambda_{a l}=211-782.8 T^{-0.5428}
$$

The average thermal conductivity could be given using integral from $T_{\text {foamz }}$ to $T_{\text {fluid }}$ :

$$
\bar{\lambda}_{\text {alz }}=211-1712.2 \times \frac{T_{\text {foamz }}^{0.4572}-T_{\text {fluid }}^{0.4572}}{T_{\text {foamz }}-T_{\text {fluid }}}
$$

For the heat transfer coefficient of natural convection, due to no restriction of Rayleigh number, Churchill's correlation could be recommended:

$$
N u_{z}=\left\{0.825+\frac{0.387 R a_{z}^{1 / 6}}{\left[1+\left(0.492 / \operatorname{Pr}_{z}\right)^{9 / 16}\right]^{8 / 27}}\right\}^{2}
$$

Which is

$$
R a_{z}=G r_{z} P r_{z}=\frac{g \rho_{z} c_{p z}\left(T_{a i r}-T_{\text {foamz }}\right) H^{3}}{v_{z} \lambda_{z} T_{\text {air }}}
$$

where $N u_{z}$ is Nusselt number, $P r_{z}$ is Prandtl number, $R a_{z}$ is Rayleigh number, $g$ is gravitational acceleration, $G r_{z}$ is Grashof number, $c_{p z}$ is the specific heat of air, $\rho_{z}$ is the density of air, $\lambda_{z}$ is the thermal conductivity of air, and $v_{z}$ is the dynamic viscosity of air.

The heat transfer coefficient of radiation can be given as follows:

$$
h_{r z}=\frac{\varepsilon \sigma\left(T_{\text {air }}^{4}-T_{\text {foamz }}^{4}\right)}{T_{\text {air }}-T_{\text {foamz }}}=\varepsilon \sigma\left(T_{\text {air }}^{2}+T_{\text {foamz }}^{2}\right)\left(T_{\text {air }}+T_{\text {foamz }}\right)
$$

where $\varepsilon$ is the surface thermal emissivity, $\varepsilon=0.2$ at $300 \mathrm{~K}$ and $\sigma$ is the Stefan-Boltzmann constant, $\sigma=5.67 \times 10^{-8} \mathrm{~W} /\left(\mathrm{m}^{2} \cdot \mathrm{K}^{4}\right)$.

With the model established by the above equations, the heat leakage and the temperature of the external wall surface of the tank can be calculated iteratively, provided that the internal temperature of the tank and the ambient temperature is determined. Since the temperature rise inside the tank is relatively slow, it is assumed that the temperature inside the tank does not change within one iteration step when calculating the heat leakage. By continuously updating the internal temperature of the tank, the heat leakage of the tank changes dynamically as the state inside the tank changes. This heat leakage model has been used to predict the evaporation rate of liquid hydrogen and liquid oxygen tanks on the 
ground. The calculated values are basically consistent with the experimental data. It indicates that the sub-model is credible. Unfortunately, the experimental data are inconvenient to show.

\subsection{Temperature Rise Model}

During the ground parking, there is a temperature rise of the densified propellants due to the tank heat leakage. The tank heat leakage $Q$ can be obtained from the heat leakage model developed in Section 1.2.

The temperature rise of the propellants is calculated as:

$$
d T=\frac{Q_{z 1}}{m \cdot \tau \cdot c_{p f l u i d}}
$$

where $m$ is the mass of cryogenic propellants in the tank, $c_{p f l u i d}$ is the constant pressure specific heat capacity, and $\tau$ is the parking time.

The propellant temperature in the tank is obtained as:

$$
T_{\text {fluid }}^{\prime \prime}=T_{\text {fluid }}^{\prime}+d T
$$

where $T_{\text {fluid }}^{\prime}$ is the fluid temperature of the current moment, and $T_{\text {fluid }}^{\prime \prime}$ is the fluid temperature of the next moment.

\subsection{Engine Thrust Model}

Cryogenic turbopump is the general term for turbine and pump, which is the core component for a rocket engine. The oxygen-rich gas drives the turbine, which pulls the pump to deliver cryogenic propellants into the combustion chamber of the engine. The thrust generated by the engine is related to the flow rate of the turbopump into the combustion chamber.

The thrust of the engine may be written as [29].

$$
F=\dot{m} \cdot V_{e}+A_{e}\left(p_{e}-p_{0}\right)
$$

where $F$ is the thrust, $\dot{m}$ is the mass flow, $V_{e}$ is the nozzle exit velocity, the $A_{e}$ is the nozzle exit cross-sectional area, $p_{e}$ is the nozzle exit pressure, $p_{0}$ is the pressure of free stream conditions.

The first term on the right side in Equation (10) is the thrust from the change of jet momentum, called dynamic thrust, and the second term is the thrust from the difference in internal and external pressure, called static thrust. In a large thrust engine, the thrust is mainly supplied by the dynamic thrust.

The turbine pump mass flow is given by [30]

$$
W_{L}=0.5 \cdot \pi \cdot d \cdot\left(d-d^{\prime}\right) \cdot\left(\frac{v l}{d-d^{\prime}}+\zeta_{\text {in }}+\zeta_{\text {out }}\right)^{-0.5} \cdot\left(2 \cdot \rho_{L} \cdot \Delta p\right)^{0.5}
$$

where $d$ is the inner diameter of the valve seat, $d^{\prime}$ is the inner diameter of the valve pin, $l$ is the length of the flow path, $v$ is the viscous loss coefficient in the flow path, $\xi_{\text {in }}$ is the inlet loss coefficient, $\xi_{\text {out }}$ is the outlet loss coefficient, $\rho_{L}$ is the density of the propellants, and $\Delta p$ is the differential pressure. From Equation (11), it is well known that the propellant flow $W_{L}$ increases with the enhancement of density $\rho_{L}$, when the effect of other loss factors is constant.

\subsection{Tank Pressurization Model}

One of the important conditions for the normal operation of the engine is to ensure that the turbopump does not suffer from cavitation. In order to prevent cavitation, tank 
pressurization is usually used. Therefore, to satisfy the required pressure of the turbopump pump inlet, the pressurization pressure in the tank is calculated as follows:

$$
p_{r}=p_{v}+\Delta p_{f}-p_{n}
$$

where $p_{r}$ is the pressurization pressure in ullage of the propellant tank, $p_{v}$ is the saturation pressure of the propellant at the inlet temperature of the turbopump, $\Delta p_{f}$ is the flow resistance loss in the feeding pipe, and $p_{n}$ is the overload pressure of the liquid column in flight.

The overload pressure $p_{n}$ is the pressure generated by the acceleration of the rocket during liftoff acting on the liquid. With the consumption of propellant in the flight and the continuous change of acceleration, $p_{n}$ is continuously changing, and in addition, $p_{n}$ is also related to the component composition of propellant.

The overload pressure $p_{n}$ is written as

$$
p_{n}=H \cdot \rho_{L} \cdot n_{x}
$$

where $H$ is the vertical height from the liquid level to the engine pump inlet, $\rho_{L}$ is the density of the propellants, and $n_{x}$ is the acceleration coefficient of the rocket.

According to the Darcy-Weisbach equation, the flow resistance loss $\Delta p_{f}$ in the feeding pipeline is given as follows:

$$
\Delta p_{f}=f \cdot \frac{L}{D} \cdot \frac{\rho_{L} v^{2}}{2}
$$

Which is

$$
f=\left\{\begin{array}{lr}
64 \cdot \operatorname{Re}^{-1} & \operatorname{Re}<2320 \\
0.025 \operatorname{Re}^{1 / 3} & 2320<\operatorname{Re}<4000 \\
0.3164 \operatorname{Re}^{-0.25} & 4000<\operatorname{Re}<10^{5} \\
0.0032+0.221 \operatorname{Re}^{-0.237} & 10^{5}<\operatorname{Re}<3 \times 10^{6}
\end{array}\right.
$$

In calculation of Reynolds number, the density of $\mathrm{SH} 2$ is taken as the weighted average of solid and LH2. The viscosity of the SH2 [31] is

$$
\mu_{s}=\mu_{l}\left(1+2.5 \alpha_{s}+10.05 \alpha_{s}^{2}+0.00273 \cdot e^{16.6 \alpha_{s}}\right)
$$

where $\mu_{S}$ is the viscosity of the $\mathrm{SH} 2, \mu_{l}$ is the viscosity of the $\mathrm{LH} 2$, and $\alpha_{s}$ is the solid content of the $\mathrm{SH} 2$.

\subsection{Wall Thickness of Tank}

The wall thickness for the thin shell tank is mainly determined by the ullage pressure, which is

$$
t=\frac{p_{g} \cdot R}{[\sigma]_{t}}
$$

where $t$ is the wall thickness of the tank, $p_{g}$ is the internal pressure of the tank design, $R$ is the radius of the shell section, and $[\sigma]_{t}$ is the permissible strength of the material of the tank at the temperature in use.

\section{Comprehensive Performance Analysis of Densified LH2/LO2}

\subsection{LH2/LO2 Tank Structure}

In order to evaluate the comprehensive performance of different cryogenic rockets after densification, the following three types of cryogenic rocket structures are compared and analyzed in the present paper, and the specific dimensions are shown in Table 1. 
Table 1. Parameters of the rocket tank structure.

\begin{tabular}{|c|c|c|c|c|c|c|c|}
\hline \multirow{2}{*}{ Table } & & \multicolumn{3}{|c|}{ LO2 } & \multicolumn{3}{|c|}{ LH2 } \\
\hline & & O-1 & O-2 & O-3 & H-1 & H-2 & H-3 \\
\hline \multirow{3}{*}{ Structure } & Diameter/m & 3.5 & 5 & 10 & 3.5 & 5 & 10 \\
\hline & Height $/ \mathrm{m}$ & 7 & 7 & 7 & 19 & 19 & 19 \\
\hline & Volume $/ \mathrm{m}^{3}$ & 67.3 & 137.4 & 549.8 & 182.8 & 373.1 & 1492.3 \\
\hline Thermal Insulation Material & Thickness/m & 0.02 & 0.02 & 0.02 & 0.02 & 0.02 & 0.02 \\
\hline
\end{tabular}

\subsection{Initial Conditions and Solution Strategy}

The ambient temperature was set at $300 \mathrm{~K}$. According to the parameters of the existing launch site, the filling flow rate of LH2 and LO2 was $5 \mathrm{~m} / \mathrm{s}$. The equivalent diameter of the filling pipeline is $200 \mathrm{~mm}$, and the equivalent length of the filling pipeline was $60 \mathrm{~m}$. In space, according to the existing thermal insulation method, the heat flux was $6 \mathrm{~W} / \mathrm{m}^{2}$.

The method of time step progression was adopted to obtain the calculation results, which were programmed by MATLAB software, called NIST database [32].

\subsection{Ground Parking Analysis after Densification}

To ensure successful launch of a rocket, several departments were required to work together, but many unexpected factors may cause the mission to be delayed during the rocket launch. If the launch of the rocket was delayed after the subcooled LH2/LO2 had already been filled into the tank, the heat leakage will lead to a decrease in the subcooling of the cryogenic fuel and affect the quality of the propellants. The temperature rise of LH2 parking is primarily related to the structural dimensions of the tank and the initial temperature of LH2, as shown in Figure 2, and LH2 tanks generally require a large volume due to the low density of the LH2. The lower the temperature of LH2 in the tank, the greater the heat leakage into the tank, and the faster the temperature rise of LH2. It can be seen from Figure 2 that, taking the $\mathrm{H}-1$ tank, as an example, the tank temperature rose by $2 \mathrm{~K}$ from $14 \mathrm{~K}$ to $16 \mathrm{~K}$, and the time was $0.67 \mathrm{~h}$. Similarly, the time to raise the temperature from $16 \mathrm{~K}$ to $18 \mathrm{~K}$ was $0.76 \mathrm{~h}$. It was found that the temperature rising curves of tanks with different sizes showed a trend from sharp to gentle. The dimensions of the tanks have a dramatic influence on the temperature rise. For the tank with the same height, the larger the diameter was, the smaller the heat leakage per unit volume was the temperature rise of LH2 in the tank was slower. As a result, it showed that the insulation structure of the conventional storage tank was not sufficient to maintain the subcooling degree of the subcooled LH2. Even for the larger H-3 tank, which had the slowest temperature rise, the subcooling degree of the densified LH2 had also been completely lost after several hours of parking. Therefore, it was necessary to adopt better thermal insulation measures or fill the liquid hydrogen into the tank first and then subcool it, or launch within a certain time after filling to ensure that the rocket storage tank can maintain the subcooled state of LH2.

Figure 3 shows the temperature rise of densified LO2 in different degrees. It can be observed from Figure 3 that the main factors affecting the parking temperature rise were also the tank size and $\mathrm{LO} 2$ temperature. The larger the diameter of the tank, the lower the heat leakage per unit volume and the lower the parking temperature rise at the same time. The temperature rise of LO2 in O-1 tank was about $1.5 \mathrm{~K}, \mathrm{O}-2$ was about $1.1 \mathrm{~K}$, and O-3 was about $0.7 \mathrm{~K}$ when the parking time was two hours. It shows that the lower the temperature of $\mathrm{LO} 2$ in the tank, the higher the temperature rise per unit time, and the absolute value of temperature difference was small. The temperature rise of densified LO2 basically had a linear relationship with time. The longer the storage time, the more the $\mathrm{LO} 2$ temperature rise in the tank. 


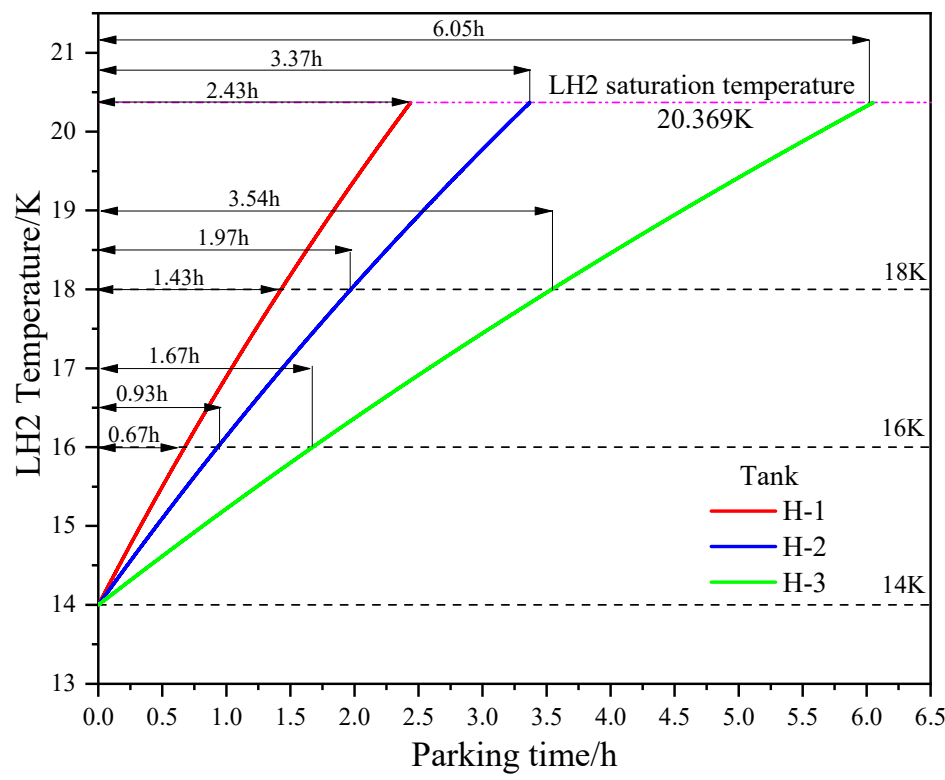

Figure 2. Temperature rise of densified LH2 parking.

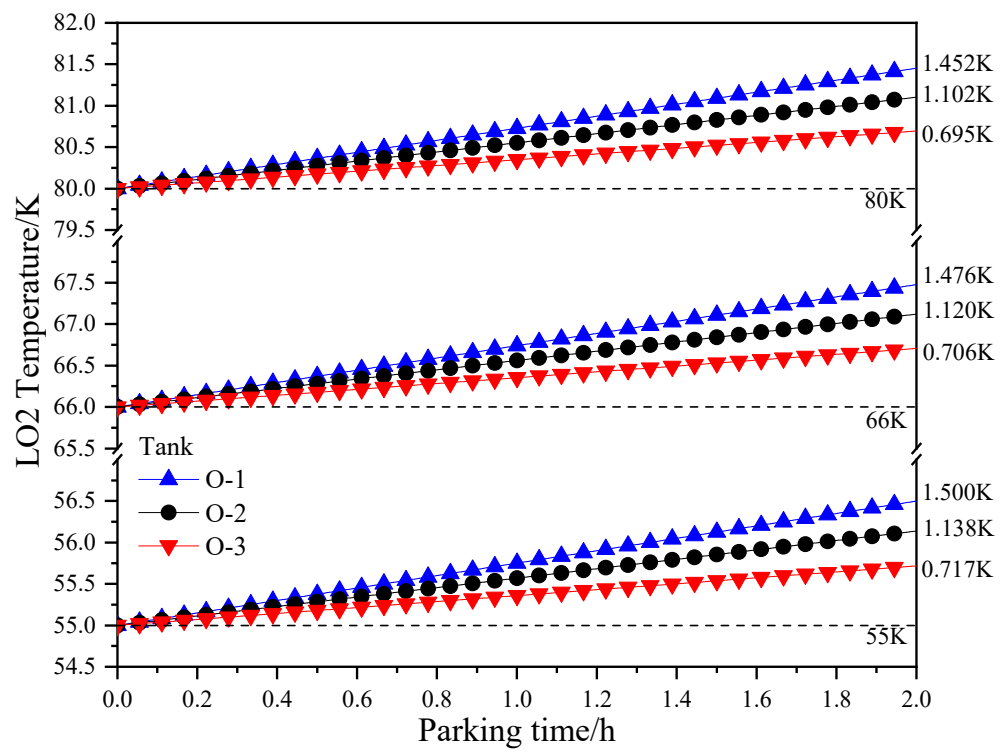

Figure 3. Temperature rise of densified LO2 parking.

Compared with the LH2 tanks, the temperature rise of the LO2 tanks was much smaller when it was parked. Although the triple point temperature of the LO2 was $35.8 \mathrm{~K}$ lower than the normal boiling point temperature, the LO2 in the triple point state will still maintain a certain subcooling degree after it is parked for several hours. This shows that the existing insulated tank with polyurethane foam was still suitable for storing subcooled LO2.

\subsection{Mass Flow Analysis of Turbopump after Densification}

When the LH2/LO2 propellant is subcooled, the density of the propellant will increase with the increase of subcooling degree. According to Equations (10) and (11), the mass flow of the turbopump will also enhance with the increase of the density of the propellant, resulting in more fuel entering the engine combustion chamber per unit time and greater thrust to promote the payload of the rocket.

As shown in Figure 4, when the saturated LO2 was subcooled at one atmospheric pressure, the density of LO2 increased with the decrease of LO2 temperature, and the increasing trend of density was approximately linear. The LO2 was subcooled to $80 \mathrm{~K}$, 
the density was $1190.46 \mathrm{~kg} / \mathrm{m}^{3}$, the relative increase was $4.32 \%$, and the mass flow of the turbopump can be increased by $2.14 \%$. When the LO2 was subcooled to $66 \mathrm{~K}$, the density was $1255.17 \mathrm{~kg} / \mathrm{m}^{3}$, the relative increase was $10.0 \%$, and the mass flow of the turbopump could be increased by $4.88 \%$. When the LO2 was subcooled to the triple point temperature of $54.36 \mathrm{~K}$, the density was $1306.08 \mathrm{~kg} / \mathrm{m}^{3}$, which increased by $14.45 \%$, and the mass flow of the turbopump can increase by $6.98 \%$.

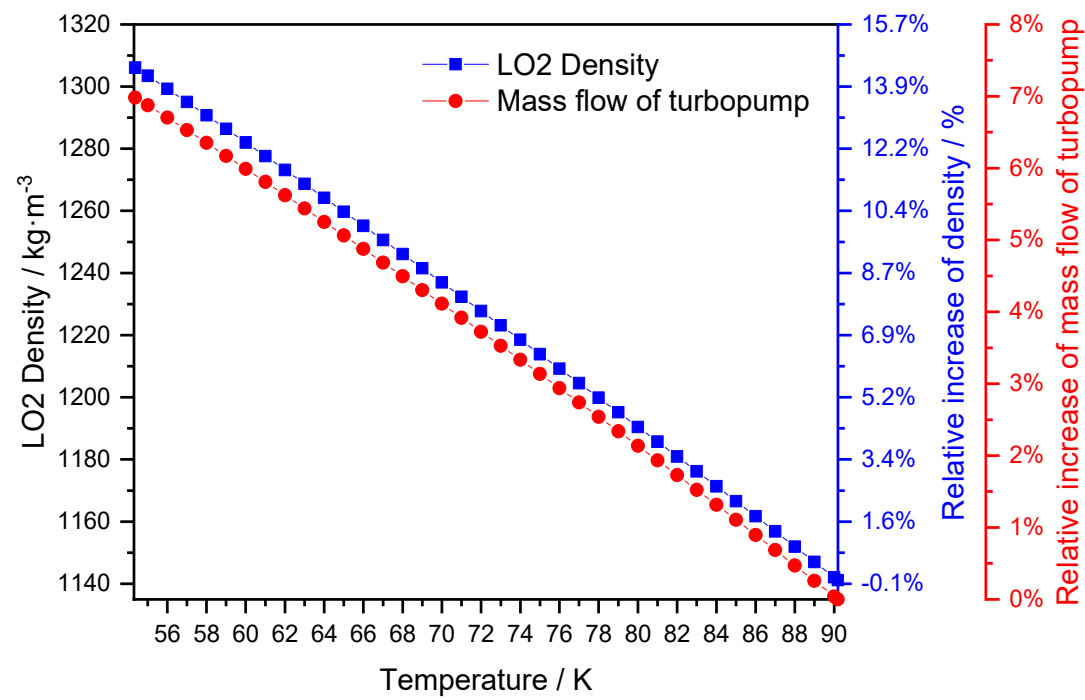

Figure 4. Effect of subcooling density of LO2 on the mass flow of the turbopump.

LH2 density was significantly lower than that of other cryogenic propellants. To increase the density of LH2, it can be subcooled to a slush state containing a certain number of solids. Figure 5 displays the relative increase of mass flow of turbopump with a change of LH2/SH2 density. It can be seen from this figure that the LH2/ SH2 density had a significant effect on the mass flow of turbopumps. When LH2 was subcooled to $18 \mathrm{~K}$, $13.9 \mathrm{~K}$, and $50 \%$ solid content, the density could increase by $3.57 \%, 8.69 \%$, and $15.03 \%$, respectively. Compared with the saturated state, the mass flow of the turbopump could increase by $1.77 \%, 4.25 \%$, and $7.25 \%$, respectively.

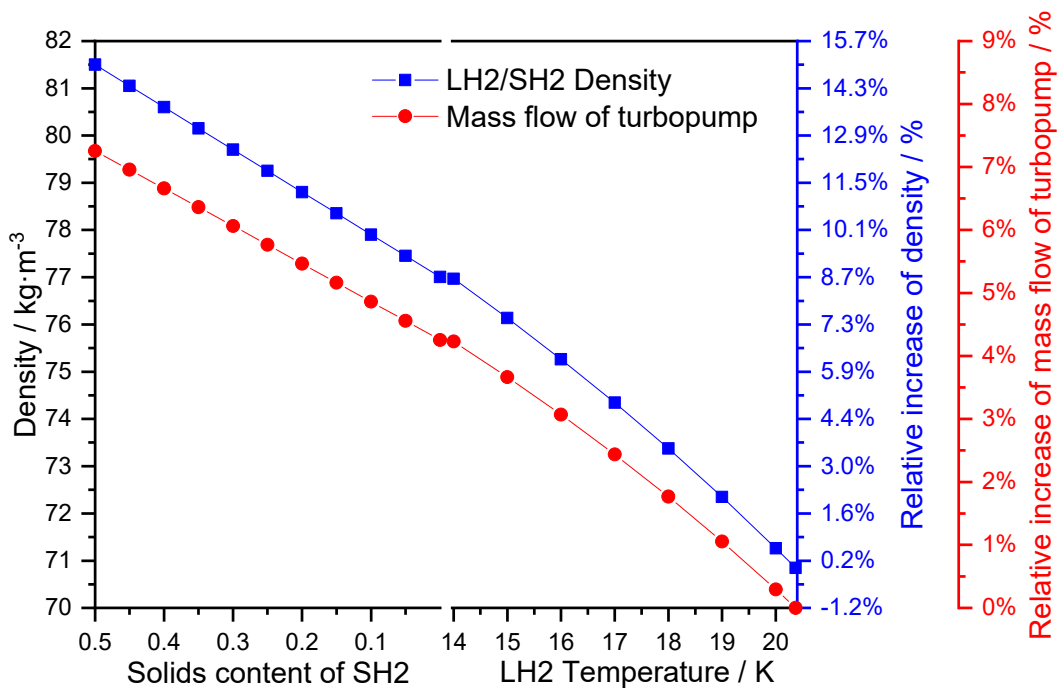

Figure 5. Effect of subcooling density of $\mathrm{LH} 2 / \mathrm{SH} 2$ on the mass flow of the turbopump.

\subsection{Rotation Speed Analysis of Turbopump after Densification}

If the mass flow of the turbopump is kept unchanged and the propellant is densified, the corresponding volume flow of the turbopump can be reduced, and then the pump speed 
can be decreased, which will bring many benefits to the engine design. For example, the turbopump speed is reduced, and the working life can be significantly improved, especially for the reusable liquid rocket engine. As shown in Figure 6, when the LH2 was densified to $\mathrm{SH} 2$ with $50 \%$ solid content, the pump speed could be decreased by about $13 \%$. When the LO2 was densified to the triple point, the pump speed could be reduced by about $12.6 \%$. The application value was very considerable.
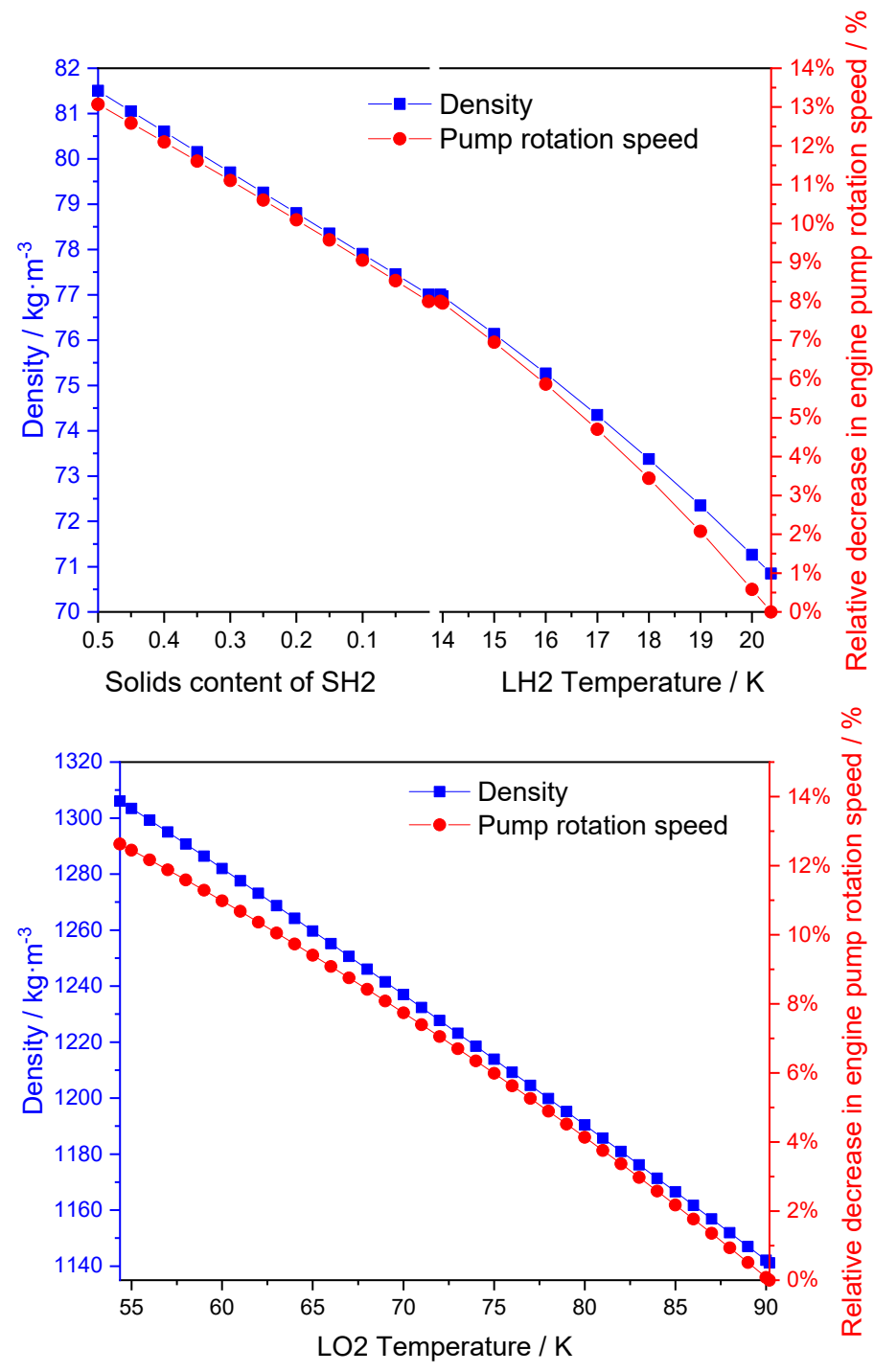

Figure 6. Relationship between LH2/LO2 densification degree and pump speed.

\subsection{Weight Reduction Analysis of the Tank after Densification}

The densified propellants are beneficial to increase the high orbit capability of the rocket. On the one hand, propellant densification can reduce the pressurization pressure required by the tank on the rocket, decrease the number of helium cylinders, and realize the weight reduction of the launch vehicle. On the other hand, densification leads to higher density and reduces the volume and mass of the storage tank.

In the process of rocket flight, it is necessary to pressurize the tank. The calculation of pressurization pressure $p_{\mathrm{r}}$ is shown in Formula (14). Under the condition of a certain subcooling degree, the saturated vapor pressure $p_{\mathrm{v}}$ and flow resistance loss of cryogenic propellants $\Delta p_{f}$ will not change. When the overload pressure term $p_{n}$ of the liquid column is zero, the maximum pressurization pressure required by the propellant tank is only related to the type and subcooling degree of propellants. Figure 7 shows the change of pressurization pressure required by the storage tank on the rocket for the LH2 subcooled to 
the triple point state, and 50\%solid content and LO2 subcooled to the triple point state. It could be clearly seen from Figure 7 that with the deepening of densification, the decrease of the saturated vapor pressure of LH2 before the triple point is the dominant factor, and the required pressurization pressure decreases significantly. When densifying to slush hydrogen, the required pressurization pressure increases slightly due to the increase of flow resistance loss, and the increased range is very small. From the triple point to the solid content of 50\%, the required pressurization pressure of the tank only increases by $1.93 \mathrm{kPa}$, while from the saturated LH2 to the triple point, the required pressurization pressure decreases by $93.5 \mathrm{kPa}$.
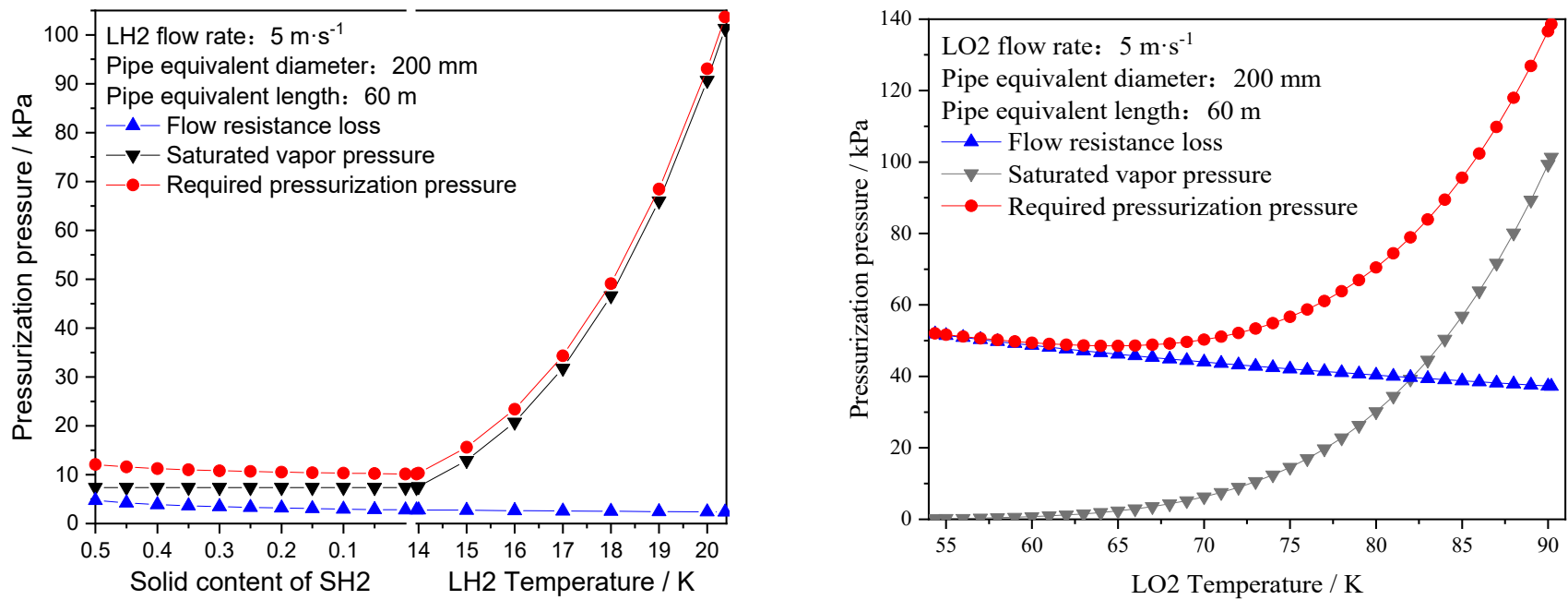

Figure 7. Relationship between $\mathrm{LH} 2 / \mathrm{LO} 2$ densification degree and required pressurization pressure of the tank.

With the deepening of densification of LO2, firstly, due to the decrease of saturated vapor pressure, the required pressurization pressure decreases rapidly. At $65 \mathrm{~K}$, the pressurization pressure reaches the lowest. When the LO2 continues to densify, the pressurization pressure begins to rise due to the dominant increase of flow resistance loss.

If the storage tank on the rocket is pressurized with helium gas, according to the above analysis, the densification of $\mathrm{LH} 2 / \mathrm{LO} 2$ can effectively reduce the pressurization pressure required by the storage tank and the helium mass consumed by the pressurization of the storage tank will also be reduced. The relationship between the densification degree of LH2/LO2 and the consumption mass of pressurized helium is shown in Figure 8. It can be observed from this figure that densifying LH2 to the triple point temperature, the consumed mass of pressurized helium can be reduced by more than $90 \%$, and in the H-3 storage tank, about $373 \mathrm{~kg}$ of helium can be reduced. When the densified LO2 was subcooled to $65 \mathrm{~K}$, the use of pressurized helium could be reduced by about $65 \%$, and the mass of pressurized helium in the O-3 tank could be reduced by about $132 \mathrm{~kg}$. The reduction of these masses does not include the cylinder to store helium gas.

In addition to reducing the consumption of pressurized helium, the decrease of pressurized pressure will reduce the design pressure of the storage tank on the rockets and further reduce the wall thickness of the storage tank. However, due to the requirement to ensure the positive pressure condition inside the tank during ground filling and parking, the design pressure of the tank could not be lower than the standard atmospheric pressure. According to Figure 7, the required pressurization pressure of LH2 at the beginning of subcooling was lower than the standard atmospheric pressure, thus the mass reduction of LH2 tank caused by this item can be ignored. When the LO2 was subcooled below $85 \mathrm{~K}$, the pressurization pressure was also lower than the saturated atmospheric pressure, and the decrease in structural mass of the tank due to the decrease in pressurization pressure will not continue to reduce. 

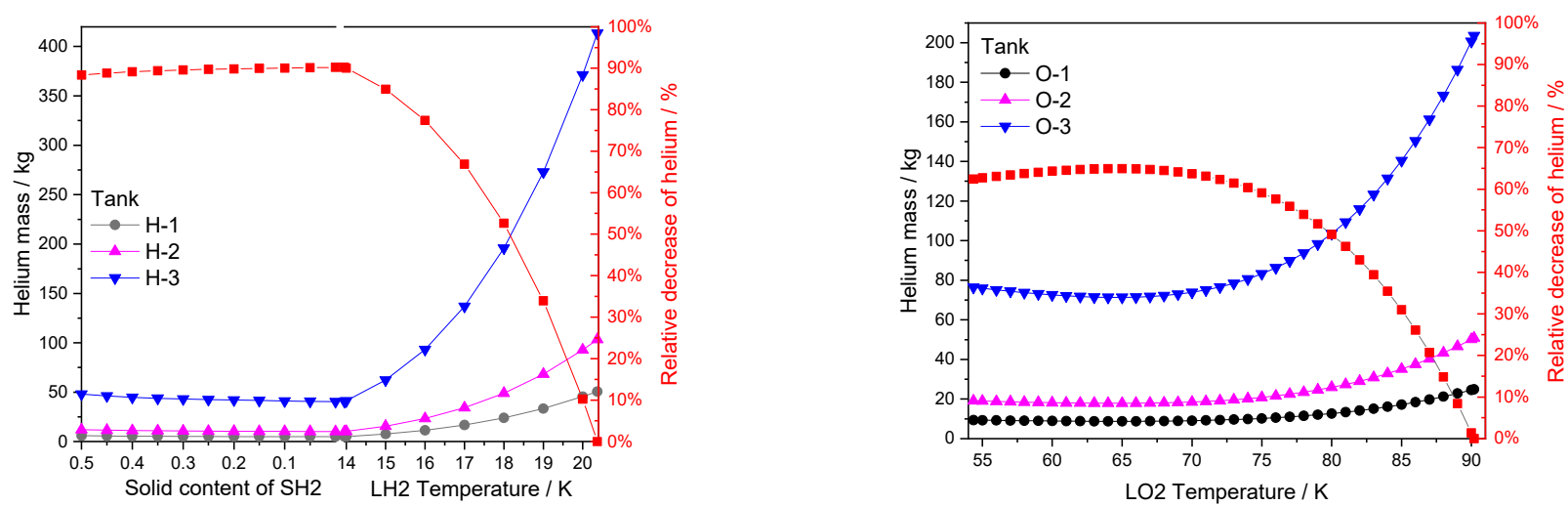

Figure 8. Relationship between LH2/LO2 densification degree and mass consumption of pressurized helium.

The mass of the tank was affected not only by the wall thickness but also by the volume. That is, the volume of the tank required to accommodate the same mass of $\mathrm{LH} 2 / \mathrm{LO} 2$ reduces with the increase of densified LH2/LO2 density, and the tank mass on the rocket was also decreased. The relationship between the relative reduction of the tank mass and the densification degree of LH2/LO2 is shown in Figure 9. It can be seen from Figure 9 that the densified LH 2 with $50 \%$ solid content can reduce the mass of three LH2 tanks by $12.4 \%$ to $14.0 \%$, respectively. The densification of LO2 to the triple point temperature can reduce the mass of three structural tanks by $32.3 \%$ to $34.3 \%$, respectively. For the same mass of propellant fuel, the weight reduction of the smaller tank is more obvious. The greater the densification degree of propellant fuel, the more the decrease of the storage tank mass on the rocket. Especially for the LO2 tank, the subcooling degree of $5 \mathrm{~K}$ can reduce the mass of the storage tank by more than $27 \%$, which is very considerable in the application.
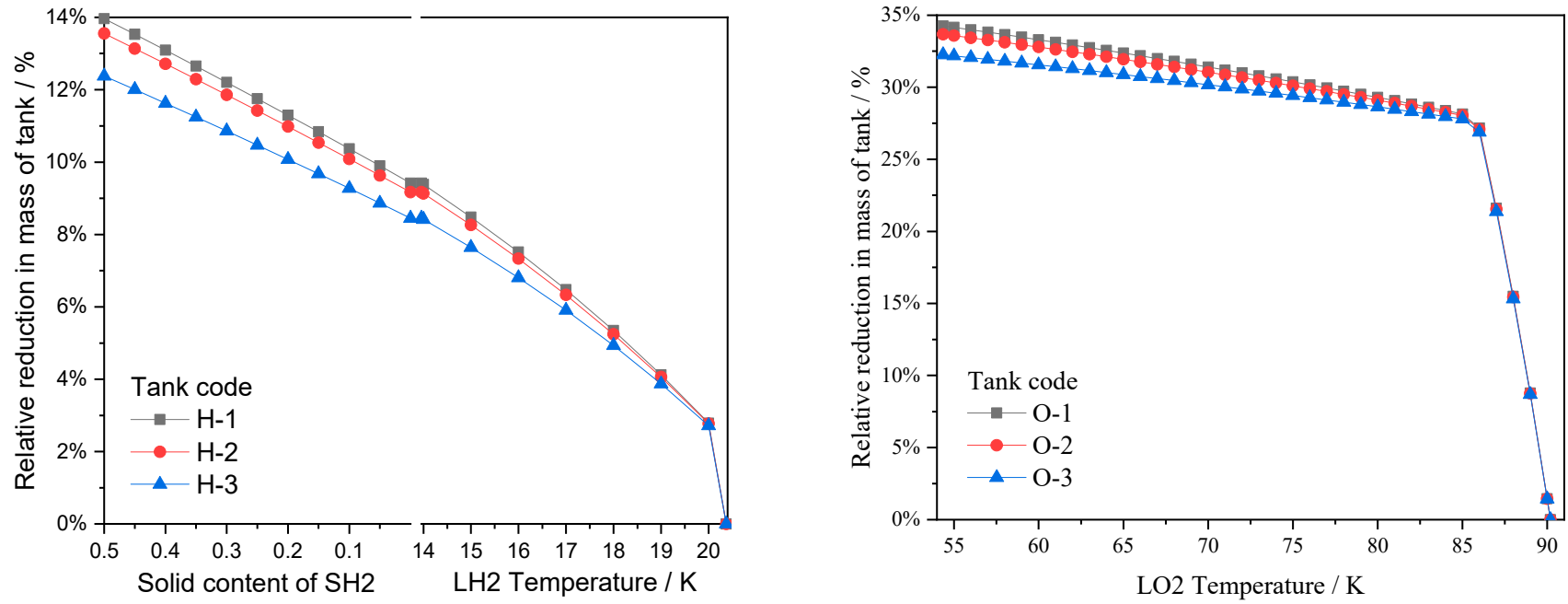

Figure 9. Relationship between $\mathrm{LH} 2 / \mathrm{LO} 2$ densification degree and tank mass.

\subsection{In-Orbit Time of Spacecraft after Densification}

Densified LH2/LO2 can accumulate more cooling capacity per unit volume due to the increase of density and enthalpy difference. The sensible cooling capacity per unit volume refers to the heat required for densified cryogenic propellants from the subcooled state to the normal boiling point state. Figure 10 shows the change of sensible cooling capacity per unit volume of LH2/LO2 with the degree of densification. It could be clearly seen from Figure 10 that when the LH2 is densified to the triple point state, the sensible cooling capacity per unit volume increases by $4.15 \mathrm{MJ} / \mathrm{m}^{3}$. When densified to the slush 
hydrogen with $50 \%$ solid content, the sensible cooling capacity per unit volume increases by $4.79 \mathrm{MJ} / \mathrm{m}^{3}$. When the LO2 from the normal boiling point to the triple point is subcooled, the sensible cooling capacity per unit volume increases by $78.7 \mathrm{MJ} / \mathrm{m}^{3}$.
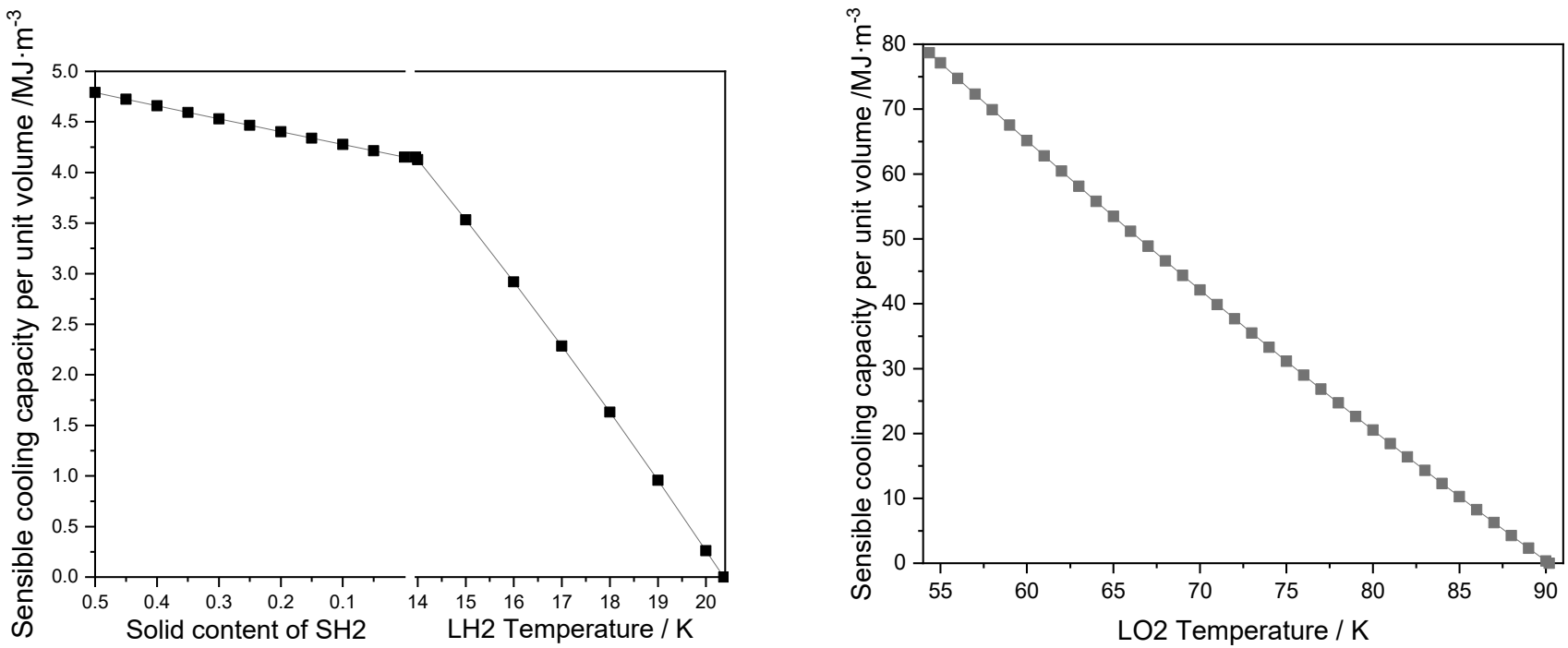

Figure 10. Relationship between $\mathrm{LH} 2 / \mathrm{LO} 2$ densification degree and the sensible cooling capacity per unit volume.

Because of the thermal performance of cryogenic propellants, even if the best thermal insulation method is adopted, the internal temperature of the propellant tank cannot be kept constant. If the cryogenic propellants are densified because the sensible cooling capacity per unit volume of propellant increases, the increased cooling capacity can effectively offset the heat leakage of the propellant tank and prolong the deep space exploration time of spacecraft. It is assumed that heat leakage per unit area is $6 \mathrm{~W} / \mathrm{m}^{2}$, and the tank filling rate is $90 \%$. It can be seen from Figure 11 that compared with the propellant in the normal boiling point state, the densification of LH2 can prolong the in-orbit time about 2-6.5 days, and the densification of LO2 can prolong the time about 20-95 days, which is of great significance for the needs of deep space exploration in the future.
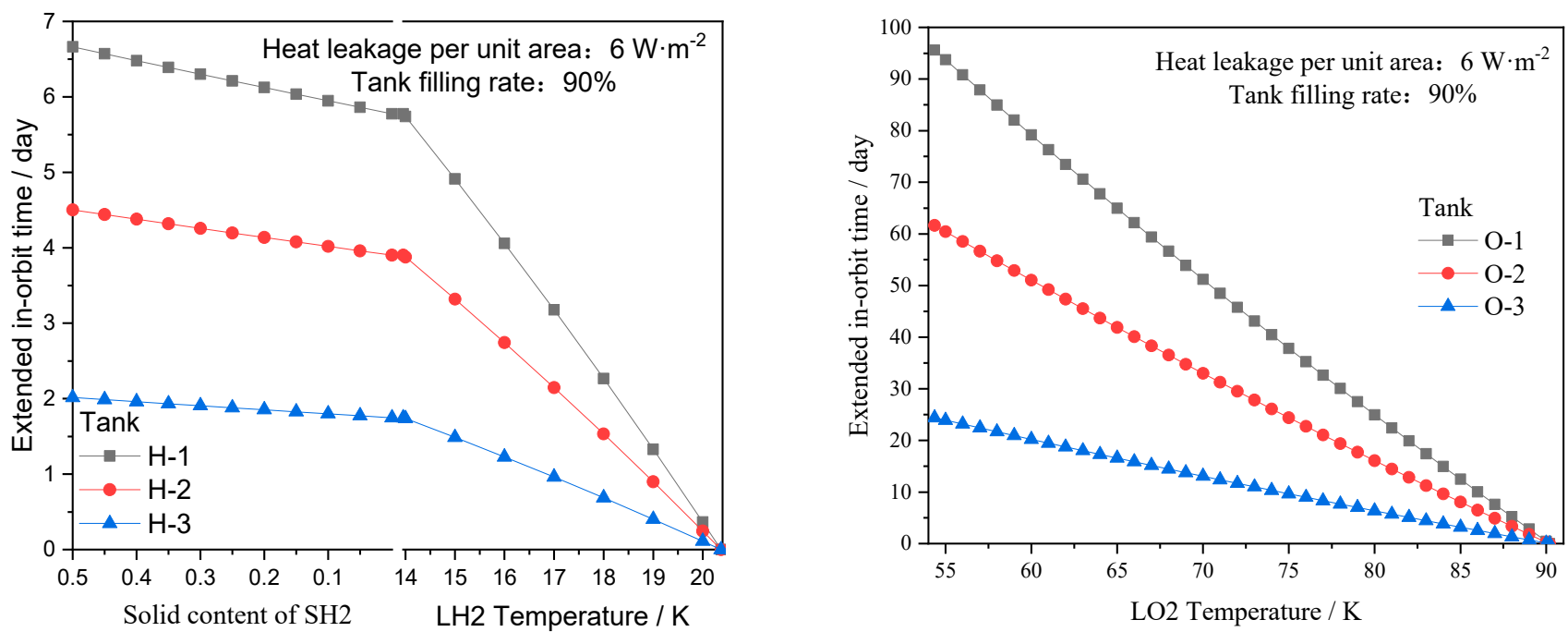

Figure 11. Relationship between $\mathrm{LH} 2 / \mathrm{LO} 2$ densification degree and extended in-orbit time. 


\section{Subcooling Combination Matching of LH2/LO2}

\subsection{Subcooling Matching at Different Mixing Ratios}

In order to make full use of the densified LH2/LO2 in the storage tank, the densification degree of LH2/LO2 needs to be controlled, otherwise, LH2/LO2 fuel will be wasted.

In $\mathrm{LH} 2 / \mathrm{LO} 2$ rocket engine, to ensure the reliable operation and reasonable combustion performance of the thrust chamber, it is necessary to ensure a certain ratio of LH2/LO2, which is called a mixing ratio. The mixing ratio of thrust chamber for the LH2/LO2 as fuel is generally designed to be about $6: 1$, and the mixing ratio of the rocket engine of the gas generator power cycle for the LH2/LO2 was generally 5.0-5.3. Taking the tank combinations of various sizes in Table 1 as an example, when the $\mathrm{O}-1, \mathrm{O}-2$, and O-3 tanks of LO2 were combined with the H-1, H-2, and H-3 tanks of LH2, respectively, the mixing ratio of complete consumption was about 5.93, whose the propellants in the normal boiling point state was applied. For the densification of LH2/LO2 as fuel, the densification degree of LH2/LO2 needs to be matched accordingly to ensure that the fuel is fully consumed according to the predetermined mixing ratio. As shown in Figure 12, for a given O-1 liquid oxygen tank and H-1 liquid hydrogen tank, each curve in the figure represents the subcooling matching the temperature of LO2 under different mixing ratios when the LH2 was subcooled from the saturated state to the slush hydrogen with $50 \%$ solid content. In other words, as long as the mixing ratio was constant, the subcooling matching relationship between LH2 and LO2 can be found according to this picture. Taking densified LH2 in the triple point state as an example, there was no intersection with the curve below the mixing ratio of 5.4 , which means that the mixing ratio during combustion can be fully guaranteed even if the LO2 was not subcooled at this time. The curves with the mixing ratio of 5.5 to 6.2 indicate that the LO2 needs the subcooled temperature to maintain the mixing ratio currently. If there is no intersection with the curves above the mixing ratio of 6.3, which means that even if the LO2 is subcooled to the triple point state, it cannot meet the requirements of the mixing ratio at this time. That is, it will cause the waste of LH2. Taking mixing ratio 6 as an example, the LO2 is required to ensure the mixing ratio for LH2 in the normal boiling point state. With the increase of LO2 subcooling degree, the LH2 subcooling degree must also increase accordingly. The LO2 in the triple point state can only match the slush hydrogen with about $35 \%$ solid content. If the solid content of slush hydrogen further increases, the mixing ratio will be reduced.

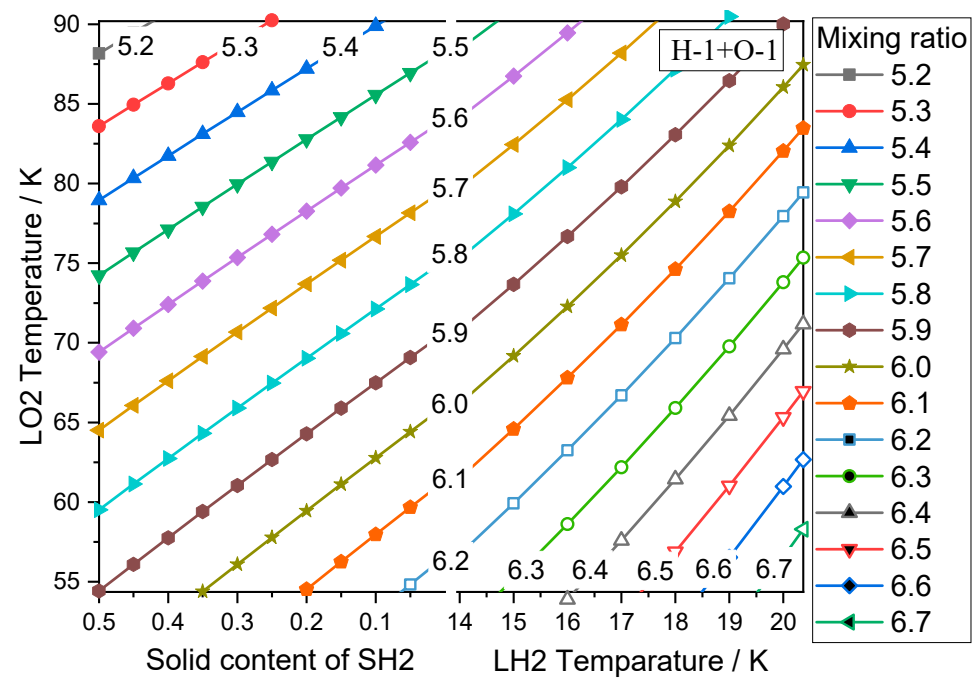

Figure 12. $\mathrm{LH} 2 / \mathrm{LO} 2$ subcooling matching at different mixing ratios.

\subsection{Optimal Subcooling Matching and Relative Thrust Increase}

An existing hydrogen-oxygen engine does not change the volume flow of the turbopump. That is, the volume flow of hydrogen/oxygen into the engine combustion chamber remains unchanged as a prerequisite. If the densified LH2 is used, the hydrogen entering 
the engine will increase. It can be observed from Figure 13 that under the condition of sufficient LO2, the engine thrust increases with the increase of subcooling degree for LH2. It is found that when the LH2 is subcooled to the slush state with $50 \%$ solid content, the relative engine thrust increases by $6.96 \%$ compared with the normal boiling point state of $\mathrm{LH} 2$. When the subcooling degree of $\mathrm{LO} 2$ is insufficient, the relative engine thrust cannot be fully burned with the increase of LH2 densification.

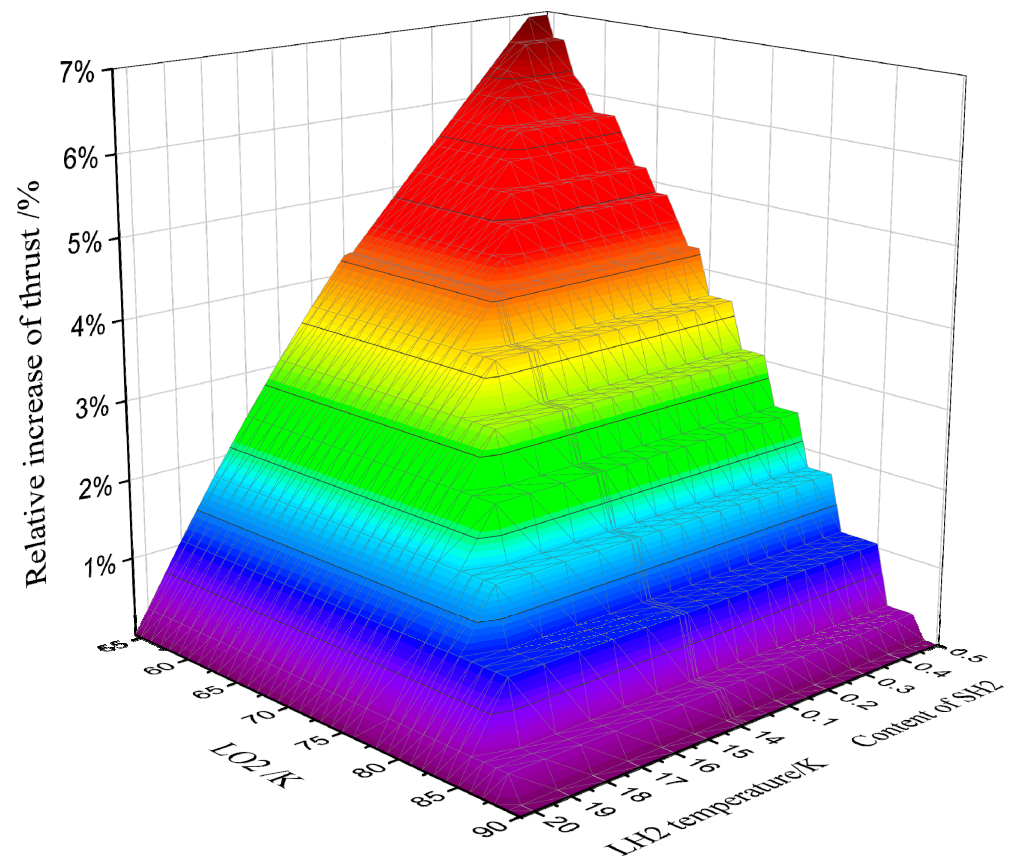

Figure 13. Relationship between $\mathrm{LH} 2 / \mathrm{LO} 2$ densification degree and relative thrust increase.

Under ideal conditions, in order to avoid the waste of subcooling energy of LO2 and ensure the full and safe combustion of LH2, there is an optimal matching subcooling temperature of $\mathrm{LH} 2 / \mathrm{LO} 2$, as shown in Figure 14. It can be clearly seen from Figure 14 that the optimal subcooling temperature of densified LH2/LO2 corresponds one by one after giving the engine volume flow and combustion mixture ratio. When the slush hydrogen with a solid content of $45 \%$ is used, the $\mathrm{LO} 2$ needs to be subcooled to $54.5 \mathrm{~K}$, which is already connected to the triple point temperature of $\mathrm{LO} 2$. For further densification of LH2, a higher density of LO2 is also required, otherwise, the combustion mixing ratio will be reduced due to insufficient $\mathrm{LO} 2$.

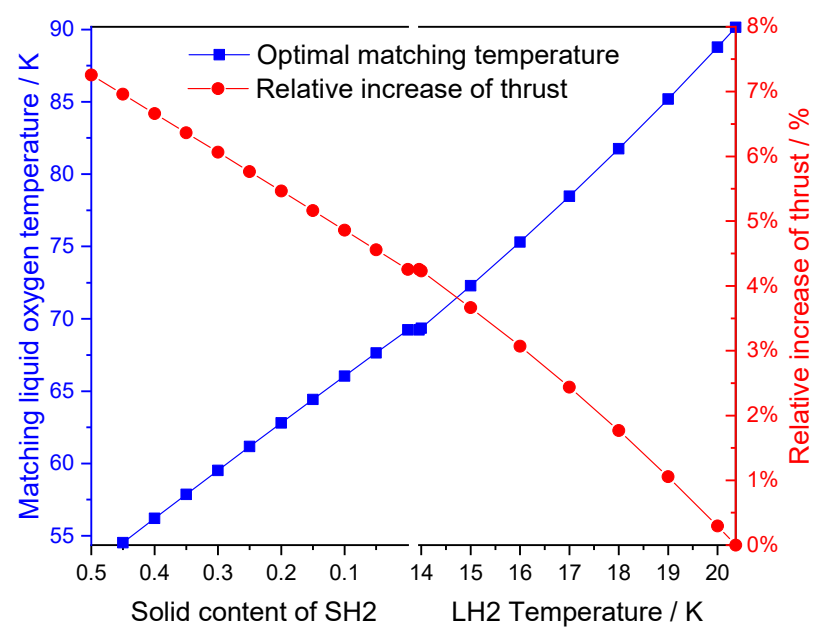

Figure 14. The optimal matching temperature of $\mathrm{LH} 2 / \mathrm{LO} 2$ and relative thrust increase. 


\section{Conclusions}

In this paper, the thermodynamic model of densified LH2/LO2 as propulsion fuel is developed, the advantages and disadvantages in the actual application are comprehensively analyzed, and the following conclusions are drawn:

The densified LH2 and LO2 will produce a greater temperature rise than the normal boiling point state during parking. It is found that increasing the diameter of the storage tank can effectively delay the temperature rise rate, but the densified LH2 will still change to the normal boiling point state after parking for several hours. Therefore, the filling method of the densified LH2 needs to be considered, such as adopting the filling scheme of filling first and then subcooling or rapid launch after filling. Compared with the densified $\mathrm{LH} 2$, the temperature rise rate of densified $\mathrm{LO} 2$ is slow, and the temperature rise per hour can be maintained within $1 \mathrm{~K}$ or even lower. In other words, the existing adiabatic storage scheme and filling scheme are suitable for the application of densified LO2.

Densified LH2/LO2 can effectively improve the working life of the engine turbopump. By densifying $\mathrm{LH} 2$ to $50 \%$ solid content and $\mathrm{LO} 2$ to the triple point, the mass flow of the engine turbopump can be increased by about $7.25 \%$ and $6.98 \%$, respectively. When the mass flow of the engine turbopump remains unchanged, its rotation speed can be reduced by about $13.1 \%$ and $12.6 \%$ for the $50 \% \mathrm{SH} 2$ and $\mathrm{LO} 2$ in the triple point state, respectively.

Densified LH2/LO2 can reduce the consumption of pressurized gas and the structural mass of the rocket tank, to reduce the taking-off mass of cryogenic launch vehicles. The densified LH2 in the triple point state can save more than $90 \%$ pressurized helium and reduce the structural mass of three LH2 tanks by about $12.4 \%$ to $14.0 \%$, respectively. The densification of $\mathrm{LO} 2$ to the triple point temperature can reduce the mass of three structural tanks by $32.3 \%$ to $34.3 \%$, respectively.

Densified LH2/LO2 can store a more sensible cooling capacity to achieve the storage of cryogenic propellants in-orbit for a long time. The $\mathrm{SH} 2$ with $50 \%$ solid content can increase the sensible cooling capacity by $4.79 \mathrm{MJ} / \mathrm{m}^{3}$ and prolong the in-orbit time of the spacecraft for about 2-6.5 days. Liquid oxygen in the triple point state can increase the sensible cooling capacity by $78.7 \mathrm{MJ} / \mathrm{m}^{3}$ and prolong the in-orbit time of spacecraft for about 24 to 95 days.

Under the condition of sufficient liquid oxygen, the LH2 can be subcooled to slush hydrogen with $50 \%$ solid content, and the relative engine thrust subsequently increases by $6.96 \%$ compared with the normal boiling point state.

It is found that there is an optimal combing matching of subcooling degree for LH2 and LO2. It is necessary to select a corresponding degree of densification to make full use of $\mathrm{LH} 2 / \mathrm{LO} 2$ when the tank volume and fuel mixing ratio are given. The $\mathrm{LO} 2$ needs to be subcooled to $69.2 \mathrm{~K}$ and $54.5 \mathrm{~K}$, when using the $13.9 \mathrm{~K} \mathrm{LH} 2$ and the SH2 with $45 \%$ solid content, respectively.

Author Contributions: Conceptualization, F.X.; methodology, F.X.; software, Q.S.; validation, F.X.; formal analysis, Q.S.; investigation, Q.S.; resources, Q.S.; data curation, Q.S.; writing-original draft preparation, F.X.; writing - review and editing, F.X.; visualization, F.X.; supervision, F.X.; project administration, F.X.; funding acquisition, F.X. All authors have read and agreed to the published version of the manuscript.

Funding: This research was funded by National Natural Science Foundation of China (51906184), China Postdoctoral Science Foundation (2021T140538, 2020M673391, 2018M633505), Fundamental Research Funds for the Central Universities (XZY012020074), and Research Fund of State Key Laboratory of Technologies in Space Cryogenic Propellants (SKLTSCP 1905).

Acknowledgments: This work was supported by National Natural Science Foundation of China (51906184), China Postdoctoral Science Foundation (2021T140538, 2020M673391, 2018M633505), Fundamental Research Funds for the Central Universities (XZY012020074), and Research Fund of State Key Laboratory of Technologies in Space Cryogenic Propellants (SKLTSCP 1905).

Conflicts of Interest: The authors declare no conflict of interest. 


\section{References}

1. Carney, R.R. Slush hydrogen production and handling as a fuel for space projects. In Advances in Cryogenic Engineering; Springer: Boston, MA, USA, 1964; pp. 529-536.

2. Keller, C. Effects of using subcooled liquid and slush hydrogen fuels on space vehicle design and performance. In Proceedings of the AIAA 3rd Propulsion Joint Specialist Conference, Washington, DC, USA, 17-21 July 1967; p. 467.

3. Friedlander, A.; Zubrin, R.; Hardy, T.L. Benefits of Slush Hydrogen for Space Missions; NASA: Cleveland, OH, USA, 1991.

4. Wilken, J. System study of slush propellants for future European launch vehicles. Space Propulsion 2018, Sevilla, Spanien, 14-18 May 2018; 14-18. Available online: https://elib.dlr.de/120361/1/039_WILKEN_update.pdf (accessed on 20 December 2021).

5. Johnson, W.; Tomsik, T.; Smudde, T.; Schnell, A.; Femminineo, M. A densified liquid methane delivery system for the Altair ascent stage. In Proceedings of the SpaceOps 2010 Conference, Huntsville, AL, USA, 25-30 April 2010; p. 1904.

6. Mustafi, S.; Canavan, E.; Johnson, W.; Kutter, B.; Shull, J. Subcooling cryogenic propellants for long duration space exploration. In Proceedings of the AIAA SPACE 2009 Conference \& Exposition, Pasadena, CA, USA, 14-17 September 2009; p. 6584.

7. Baik, J.H.; T-Raissi, A. R\&D processes for increasing density of cryogenic propellants at FSEC. Cryogenics 2004, 44, 451-458.

8. Lak, T.; Lozano, M.; Neary, D. Propellant densification without use of rotating machinery. In Proceedings of the 38th AIAA/ASME/SAE/ASEE Joint Propulsion Conference \& Exhibit, Indianapolis, IN, USA, 7-10 July 2002; p. 3599.

9. Xie, F.S.; Lei, G.; Wang, L.; Xing, K.W.; Li, Y.Z. Performance advantages and application prospects of subcooled cryogenic propellants. J. Xi'an Jiaotong Univ. 2015, 49, 16-23.

10. Xie, F.S.; Li, Y.Z.; Wang, Y. Performance evaluation on ground loading systems of cryogenic propellants. Asia-Pac. J. Chem. Eng. 2017, 12, 993-1011. [CrossRef]

11. Xie, F.S.; Li, Y.Z.; Wang, L.; Ma, Y. Feasibility analysis and application consideration of a rapid method to obtain subcooled cryogenic propellants. Appl. Therm. Eng. 2017, 118, 82-89. [CrossRef]

12. Xie, F.S.; Li, Y.Z.; Wang, L. Study on subcooled technology for cryogenic propellants. J. Aerosp. Power 2017, 32, 762-768.

13. Xie, F.S.; Li, Y.Z.; Zhu, K.; Ma, Y.; Wang, J. Cooling behaviours of liquid hydrogen by helium gas injection. Heat Mass Transf. 2019, 55, 2373-2390. [CrossRef]

14. Fazah, M.M. STS Propellant Densification Feasibility Study Data Book; National Aeronautics and Space Administration, George C. Marshall Space Flight Center: Huntsville, AL, USA, 1994.

15. Ewart, R.O.; Dergance, R.H. Cryogenic Propellant Densification Study; NASA CR-159438; NASA: Cleveland, OH, USA, 1978.

16. Stanley, D.O.; Piland, W.M. Technology Requirements for Affordable Single-Stage Rocket Launch Vehicles; NASA: Cleveland, OH, USA, 2004.

17. Notardonato, J.J.; Masters, P.A. High Density Propellant for Single Stage to Orbit Vehicles; NASA: Cleveland, OH, USA, 1976.

18. Lak, T.; Lozano, M.; Tomsik, T. Advancement in cryogenic propulsion system performance through propellant densification. In Proceedings of the 32nd Joint Propulsion Conference and Exhibit, Lake Buena Vista, FL, USA, 1-3 July 1996; p. 3123.

19. Hardy, T.L.; Whalen, M.V. Technology issues associated with using densified hydrogen for Space vehicles. In Proceedings of the 28th AIAA/SAE/ASME/ASEE Joint Propulsion Conference \& Exhibit, AIAA, Reston, VA, USA, 6-8 July 1992.

20. Tomsik, T. Performance tests of a liquid hydrogen propellant densification ground support system for the X33/RLV. In Proceedings of the 33rd AIAA/ASME/ASEE Joint Propulsion Conference \& Exhibit, AIAA, Reston, VA, USA, 6-9 July 1997 ; p. 2976.

21. Nguyen, K.; Knowles, T.E. Propellant densification for launch vehicles: Simulation and testing. In Proceedings of the 38th AIAA/ASME/SAE/ASEE Joint Propulsion Conference \& Exhibit, AIAA, Indianapolis, IN, USA, 7-10 July 2002 ; p. 4293.

22. William, D.G.; Timothy, E.K.; Thomas, M.T. Propellant densification for launch vehicles: Simulation and testing. In Proceedings of the 35th AIAA/ASME/SAE/ASEE Joint Propulsion Conference \& Exhibit, AIAA, Los Angeles, CA, USA, 20-24 June 1999; p. 2335.

23. Sumrall, P. Ares V Overview. In Proceedings of the 3rd Space Exporation Conference, Denver, CO, USA, 26-28 February 2008; p. 16.

24. Stahl, H.P.; Sumrall, P.; Hopkins, R. Ares V launch vehicle: An enabling capability for future space science missions. Acta Astronaut. 2009, 64, 1032-1040. [CrossRef]

25. Swanger, A.M.; Notardonato, W.U.; Fesmire, J.E.; Jumper, K.M.; Johnson, W.L.; Tomsik, T.M. Large scale production of densified hydrogen to the triple point and below. IOP Conference Series: Materials Science and Engineering. IOP Publ. 2017, $278,012013$.

26. Swanger, A. Large Scale Cryogenic Storage with Active Refrigeration. Master's Thesis, University of Central Florida, Orange County, FL, USA, 2018.

27. Notardonato, W.U.; Swanger, A.M.; Jumper, K.M.; Fesmire, J.E.; Tomsik, T.M.; Johnson, W.L. Large-Scale Production of Densified Hydrogen Using Integrated Refrigeration and Storage. In Proceedings of the 53rd Joint Propulsion Conference, Atlanta, GA, USA, 10-12 July 2017.

28. Available online: https://en.wikipedia.org/wiki/Falcon_9 (accessed on 20 December 2021).

29. Sforza, P.M. Theory of Aerospace Propulsion; Butterworth-Heinemann: Oxford, UK, 2012.

30. Li, W. Turbine drive system on test equipment of high presure liquid oxygen turbine pump. Rocket. Propuls. 2000, 3, 50-60.

31. Thomas, C.U.; Muthukumar, M. Three-body hydrodynamic effects on viscosity of suspensions of spheres. J. Chem. Phys. 1991, 94, 5180-5189. [CrossRef]

32. Lemmon, E.W.; Huber, M.L.; Mclinden, M.O. NIST Standard ReferenceDatabase 23: Reference Fluid Thermodynamic and Transport Properties-REFPROP. 9.0; National Institute of Standards and Technology: Gaithersburg, MD, USA, 2010. 